\title{
Contemporary management of prenatally diagnosed spina bifida aperta - an update
}

\author{
Przemyslaw Kosinski ${ }^{1}$, Robert Brawura Biskupski Samaha ${ }^{1}$, Michal Lipa ${ }^{1}$, Miroslaw Wielgos ${ }^{1}$, \\ Thomas Kohl² \\ ${ }_{1}^{1} 1^{\text {st }}$ Department of Obstetrics and Gynecology, Medical University of Warsaw, Poland \\ ${ }^{2}$ German Center for Fetal Surgery \& Minimally-Invasive Therapy (DZFT), University Hospital Mannheim (UMM), Germany
}

\begin{abstract}
Spina bifida aperta is a relatively common congenital defect that occurs in the general population. Once the disorder has been diagnosed, a discussion, that can be emotionally-charged, ensues about whether to treat it prenatally or to only offer surgery postnatally. Given that there are good arguments for and against both options, it is of paramount importance to gain a good understanding of the major advantages and disadvantages of the various surgical approaches. The aim of our paper is to summarize current knowledge about spina bifida and the potential benefits of prenatal surgery.
\end{abstract}

Ginekologia Polska 2018; 89, 11: 637-641

\section{INTRODUCTION}

Neural tube defects are the most common of all congenital central nervous system anomalies and are a common cause of chronic disability in the general population. Each year 300.000 babies worldwide are born with a neural tube defect [1]. The signs and symptoms associated with neural tube defects have been characterised in the "two-hit hypothesis"; in which the first "hit" is the embryological malformation itself and the second "hit" is the secondary damage caused by prolonged exposure of the neural tissue to the intra-amniotic milieu [2].

In general, neural tube defects can occur in two major forms: spina bifida aperta (SBA), where there is an open lesion on the spine, and spina bifida occulta, in which the lesion is closed. Approximately $80 \%$ of all neural tube defects are "open" with myelomeningocele, meningocele, encephalocele, and anencephaly being the most common forms.

Of the open-lesion forms, myelomeningocele occurs due to failure of the neural tube to close in the first four weeks after conception and sometimes can be visualised by ultrasound, as a fluid-filled sac containing spinal cord tissue and nerves, as early as first trimester of pregnancy. The least differentiated form of SBA is myeloschisis where there is an incomplete closure of the primary neural plate which results in a cleft spinal cord where the edges are flush with the defect [3].

Spina bifida occulta, the closed-lesion form of neural tube defects, is where neural tissue is not exposed but covered by skin. This disorder may be recognized by dysplastic skin, or a tuft of hair, dimple, birthmark, lump, vestigial tail, as well as other forms of spinal dysraphism. The occulta malformation has a far better prognosis than spina bifida aperta, and therefore during prenatal diagnosis must be differentiated from the latter.

The presence of SBA means that the neural tissue gets progressively damaged from incessant exposure to fetal stools, the amniotic fluid and mechanical factors over the course of gestation [4]. In general, the extent and severity of postnatal neurological deficits depend on the segmental level of the lesion. Functional motor levels correlate with anatomic lesions in around $39 \%$ of patients. Yet in more than half of patients who did not undergo fetal surgery the correlation is less optimistic then we assume because, although the anatomical level suggests a better prognosis, in reality the neurological outcome is worse as a result of the functional level being two levels higher than the anatomical level [5]. 
Wheelchair use can be anticipated in $90 \%$ of patients with a thoracic lesion, in $45 \%$ with a lumbar lesion and in $17 \%$ with a sacral lesion [6].

Furthermore, SBA is usually associated with Chiari-type-II-malformation and hydrocephalus. Chiari-type-II-malformation is the downward displacement of the cerebellar vermis and brainstem into the cervical vertebral canal [7]. More than $80 \%$ of affected individuals require a ventriculoperitoneal (VP) shunt to divert cerebrospinal fluid from brain ventricles to decompress the hydrocephalus. The VP shunting rate depends on the lesion level, where a higher shunting rate is needed for higher level lesions.

In most SBA cases, bladder and bowel incontinence are also be observed. These deficiencies may require intermittent bladder catheterization and enemas. It has been estimated that more than $80 \%$ of young adults with spina bifida have social bladder continence and almost half of them have scoliosis. In some cases, recurrent urinary tract infections, vesicoureteral reflux, and upper urinary tract dilation occur.

A study by Bowman et al. [8] that summarised a 25year period of follow-up of 71 SBA patients, found that at least $75 \%$ of SBA children can be expected to reach early adulthood. Surprisingly, and most likely in contrast to the expectations of most fetal-medicine specialists, $85 \%$ of the patients in the study were attending or had graduated from high school and/or college.

In a recent cohort study by Borgstedt-Bakke et al., $14(7 \%)$ of 200 patients with spina bifida died in the first year of life; and most of these died in the first three months of life from pneumonia, meningitis, peritonitis, pyelonephritis or sepsis [9].

From the above it becomes clear, that postnatal management of patients with neural tube defects is challenging and at best involves multiple disciplines to ensure the best possible outcome and quality of life for affected patients.

\section{PRENATAL DIAGNOSIS}

In the 1980s the main method of screening for open spina bifida was by maternal serum a-fetoprotein at around 16 weeks of gestation, and the method of diagnosis was amniocentesis and the measurement of amniotic fluid a-fetoprotein and acetyl cholinesterase.

Nowadays, most cases of spina bifida aperta are diagnosed during routine second trimester anomaly scans at 20-22 weeks of gestation. The diagnosis is commonly achieved not by identification of the malformation itself but by the indirect cranial and cerebellar signs (respectively, the lemon and banana signs) first described by Nicolaides et al. [10].

Recently, even first trimester diagnosis is possible by sonographic assessing intracranial translucency and the posterior brain region [11]. It has even been suggested that this screening technique could be incorporated into routine fetal sonographic assessments at 11-13 weeks of gestation [12].

\section{PRENATAL COUNSELLING}

In many European countries, the current practice of patient counselling after the prenatal diagnosis of spina bifida includes offering the following treatment options:

1. Pregnancy carried to term, then postnatal closure.

2. Fetal surgery.

3. Delivery at term and compassionate care.

4. Termination of pregnancy.

Given the grave consequences of SBA described in the literature and summarised above, the biggest risk to fetal survival is because of prenatal diagnosis of the disease. When confronted with the prognosis of lower limb paralysis, bladder and bowel malfunction, cerebral malformations and hydrocephalus, patients opt for termination at a high rate; for instance, the rate described in a large cohort of prenatally diagnosed cases in Germany was as high as 90\% [13].

\section{PRENATAL MANAGEMENT}

The management options for patients with SBA babies that are carried to term have dramatically widened over the past three decades. Broadly speaking, there are now three possible therapeutic routes: postnatal repair, prenatal in-utero repair by open fetal surgery, and prenatal in-utero repair by minimally-invasive fetoscopy.

Whereas postnatal surgery protects against infections and is often performed for cosmetic reasons, it has the disadvantage of being unable to restore the infant's neurological functions that were lost in-utero. In contrast, fetal surgery results in improved neurological function in most cases because it prevents the further progression of the disease process during the final four months of gestation. The rationale for offering prenatal SBA repair was arrived at based on animal studies, which showed that prenatal coverage of the malformation preserves neurological function and can even reverse hindbrain herniation $[14,15]$.

Experience with open and minimally-invasive in utero surgeries in human subjects shows similar results, including a lower incidence of shunt-dependent hydrocephalus. It has to be stressed that despite the benefits of fetal SBA surgery, postnatally most patients will still exhibit neurological signs and symptoms. Yet these are ameliorated when compared with those exhibited by patients who were first operated on postnatally. A recent American College of Obstetricians and Gynecologists Committee Opinion states that patients with prenatally diagnosed SBA who meet the criteria for in-utero repair should, nevertheless, be offered all management options [16]. 


\section{OPEN FETAL SURGERY FOR SPINA BIFIDA IN THE POST-MOMS ERA}

During "open" SBA surgery, which means following maternal laparotomy and hysterotomy, the lesion may either be closed primarily with the aid of skin and muscle flaps or closed with a synthetic patch.

Between 2003 and 2010, the prospective randomized trial known as the "Management of Myelomeningocele Study"(MOMS), sought to randomized 200 patients at three participating US fetal surgery centres, to compare the open surgical approach and the postnatal repair approach. The study considered two outcomes: the first, measured at 12 months, was death or need for a ventricular shunt; and the second, measured at 30 months, was a composite score of standardized tests for mental and motor development. The trial was stopped after only 183 patients were randomized and after 158 patients had undergone a planned interim analysis, which showed that there were statistically significant improved outcomes after prenatal spina bifida treatment [17]. Moreover, the proportion of infants in the study who showed no evidence of hindbrain herniation was higher in the prenatal surgery group (36\%) compared with the postnatal surgery group (4\%). These children from the prenatal repair group also had higher chances of walking without orthotics and had better motor function than those from the postnatal repair group. An improvement in functional motor level by two or more levels was seen in $32 \%$ and by one or more levels in $11 \%$ of the prenatal surgery group, compared with $12 \%$ and $9 \%$ respectively, in the postnatal repair group [1].

Major complications related to prenatal surgery reported in the MOMS trial were oligohydramnios, separation of membranes, membranes rupture and preterm delivery. During the study, in which both groups were delivered by Cesarean-section at approximately 37 weeks of pregnancy, only $64 \%$ of the patients had an intact and well-healed hysterectomy scar, and $10 \%$ had some form of uterine dehiscence [18].

Another study by Wilson et al., which analysed 34 patients after open prenatal spina bifida repair via hysteretomy, found $18 \%$ of patients had uterine rupture or dehiscence complications; and $3 \%$ of their patients required a hysterectomy at the time of the caesarean section [19]. It was clear that there were two conflicting outcomes emerging: while prenatal surgery improved neonatal outcomes, because of the uterine entry via hysteretomy, it also increased maternal and obstetric risks.

\section{MINIMALLY-INVASIVE FETAL SURGERY FOR} SBA

In order to minimize maternal injury from open fetal surgery, Brunner et al. and Kohl et al. pioneered mini- mally-invasive surgery techniques for SBA [20]. Brunner's minimally-invasive contribution was fetoscopic surgery, which he subsequently relinquished because it still required laparotomy and because there were technical difficulties and complications. However, Kohl et al. reported in 2006 a minimally-invasive fetoscopic approach wherein intraamniotic access is achieved entirely percutaneously by using three ports. Following partial removal of the amniotic fluid, the amniotic cavity is insufflated with $\mathrm{CO}_{2}$ to improve visualisation; and the placode is dissected free and covered with a collagen patch that is then sutured to the surrounding skin [21].

Even in Kohl's first SBA patients, independent investigators found statistically better sensory and motor functions of the lower extremities as well as a lower shunt rate [22]. However, to date, the procedure is associated with a $15 \%$ percent risk of fetal demise, and it has met with harsh criticism from some [23].

Following the development of a special protocol for achieving safe maternal and fetal anesthesia during fetoscopic surgery for spina bifida [24], all the fetuses of a more recent cohort of 51 who were operated on by Kohl survived prenatal surgery [25]. The Neurological results of this group were similar to the earlier group of Kohl's patients. Yet a high rate of premature rupture of the membranes (84\%) that was seen following this approach, shows that further improvement of the technique is required. Fortunately, after fetoscopic surgery, about $90 \%$ of patients are born beyond the $30^{\text {th }}$ week of gestation. To date, the risk of severe preterm complications has become much lower in the hands of experienced neonatologists. The mean gestational age at delivery stands at approximately 33 weeks $[25,26]$.

In 2016 Pedreira et al. published data on the initial results of a Brazilian study of minimally-invasive fetoscopic SBA repair [27]. Whereas the study's technique for fetal access and amniotic insufflation was adopted from Kohl's method, in contrast to his approach, Pedreira covered the dissected neural tissue with a biocellulose patch and closed the skin over the patch with a single running suture. Similar to Kohl's experience, most of Pedreira's patients benefitted by exhibiting impressive neurological function and a low shunt-rate but they also experienced premature membrane ruptures and delivered at a mean gestational age of 32 weeks.

Another approach described by Belfort et al., is surgery via laparotomy and exteriorization of the uterus [28]. Their approach makes it possible to plicate the membranes to the uterine wall by transuterine-transmembrane stay sutures before placing the trocars into the amniotic cavity. Furthermore, the insufflation gas was humidified and warmed to further potentially decrease any damage to the chorioamniotic membranes. The dissected placode was then sutured (including skin and dura) by a running suture. Following 
this approach, the authors reported similar neurological benefits to Kohl and Pedreira, and they also reported a much lower rate of premature rupture of membranes (23\%). Most encouragingly in their study, the mean gestational age at delivery reached 38 weeks [29].

\section{SUMMARY}

Fetal SBA surgery is a rapidly advancing field as it holds out the promise of improving bladder, bowel and lower limb functions and of reducing the need of hydrocephalus shunting in most prenatally operated fetuses. The major concern of open fetal surgery for SBA stems from the marked maternal trauma from laparotomy and hysterotomy. In MOMS patients, a uterine dehiscence rate of $12.5 \%$ was reported. Yet in more recent studies of patients, this rate has been lowered by technical modifications [30].

In contrast to open repair, minimally-invasive techniques limit maternal injury and avoid both laparotomies and hysterotomies. Consequently, following all of the fetoscopic approaches used, uterine dehiscence remains absent. Because all fetoscopic procedures provide a simpler coverage of the neural tissue than their open counterpart, which promotes closure of the lesion by several layers, there seems to be less iatrogenic damage to the neural tissue from fetoscopic surgery [31].

However, further technical improvements are desired in the fully percutaneous approaches with the goal of decreasing the still too-high rate of premature rupture of membranes and to prolong pregnancy. In this respect, the experience of Belfort et al. provides a way forward.

\section{Conflict of interest}

All Authors declare no conflicts of interest.

\section{Financial disclosure}

This research was not funded by any organization.

\section{REFERENCES}

1. Moldenhauer JS, Adzick NS. Fetal surgery for myelomeningocele: After the Management of Myelomeningocele Study (MOMS). Semin Fetal Neonatal Med. 2017; 22(6): 360-366, doi: 10.1016/j.siny.2017.08.004, indexed in Pubmed: 29031539.

2. Adzick NS. Fetal surgery for spina bifida: past, present, future. Semin Pediatr Surg. 2013; 22(1): 10-17, doi: 10.1053/j.sempedsurg.2012.10.003, indexed in Pubmed: 23395140.

3. Mohd-Zin SW, Marwan Al, Abou Chaar MK, et al. Spina Bifida: Pathogenesis, Mechanisms, and Genes in Mice and Humans. Scientifica (Cairo). 2017; 2017: 5364827, doi: 10.1155/2017/5364827, indexed in Pubmed: 28286691.

4. Mitchell LE, Adzick NS, Melchionne J, et al. Spina bifida. Lancet. 2004; 364(9448): 1885-1895, doi: 10.1016/S0140-6736(04)17445-X, indexed in Pubmed: 15555669.

5. Rintoul NE, Sutton LN, Hubbard AM, et al. A New Look at Myelomeningoceles: Functional Level, Vertebral Level, Shunting, and the Implications for Fetal Intervention. PEDIATRICS. 2002; 109(3): 409-413, doi: 10.1542/peds.109.3.409.

6. Cochrane DD, Wilson RD, Steinbok $\mathrm{P}$, et al. Prenatal spinal evaluation and functional outcome of patients born with myelomeningocele: informa- tion for improved prenatal counselling and outcome prediction. Fetal Diagn Ther. 1996; 11(3): 159-168, doi: 10.1159/000264297, indexed in Pubmed: 8739582.

7. Williams H. A unifying hypothesis for hydrocephalus, Chiari malformation, syringomyelia, anencephaly and spina bifida. Cerebrospinal Fluid Res. 2008; 5: 7, doi: 10.1186/1743-8454-5-7, indexed in Pubmed: 18405364.

8. Bowman RM, McLone DG, Grant JA, et al. Spina bifida outcome: a 25-year prospective. Pediatr Neurosurg. 2001; 34(3): 114-120, doi: 10.1159/000056005, indexed in Pubmed: 11359098.

9. Borgstedt-Bakke JH, Fenger-Grøn M, Rasmussen MM. Correlation of mortality with lesion level in patients with myelomeningocele: a population-based study. J Neurosurg Pediatr. 2017; 19(2): 227-231, doi: 10.3171/2016.8.PEDS1654, indexed in Pubmed: 27911247.

10. Van den Hof MC, Nicolaides $\mathrm{KH}$, Campbell J, et al. Ultrasound screening for spina bifida: cranial and cerebellar signs. Lancet. 1986; 2(8498): 72-74, indexed in Pubmed: 2425202.

11. Chaoui R, Nicolaides KH. Detecting open spina bifida at the 11-13-week scan by assessing intracranial translucency and the posterior brain region: mid-sagittal or axial plane? Ultrasound Obstet Gynecol. 2011; 38(6): 609-612, doi: 10.1002/uog.10128, indexed in Pubmed: 22411445.

12. Chaoui R, Nicolaides KH. From nuchal translucency to intracranial translucency: towards the early detection of spina bifida. Ultrasound Obstet Gynecol. 2010; 35(2): 133-138, doi: 10.1002/uog.7552, indexed in Pubmed: 20101633.

13. Bahlmann F, Reinhard I, Schramm T, et al. Cranial and cerebral signs in the diagnosis of spina bifida between 18 and 22 weeks of gestation: a German multicentre study. Prenat Diagn. 2015; 35(3): 228-235, doi: 10.1002/pd.4524, indexed in Pubmed: 25346419.

14. Meuli M, Meuli-Simmen $C$, Yingling $C D$, et al. In utero repair of experimental myelomeningocele saves neurological function at birth. J Pediatr Surg. 1996; 31(3): 397-402, indexed in Pubmed: 8708911.

15. Paek BW, Farmer DL, Wilkinson CC, et al. Hindbrain herniation develops in surgically created myelomeningocele but is absent after repair in fetal lambs. Am J Obstet Gynecol. 2000; 183(5): 1119-1123, doi: 10.1067/mob.2000.108867, indexed in Pubmed: 11084552.

16. Committee on Obstetric Practice, Society for Maternal-Fetal Medicine. Committee Opinion No. 720 Summary: Maternal-Fetal Surgery for Myelomeningocele. Obstet Gynecol. 2017; 130(3): 164-167, doi: 10.1097/AOG.0000000000002294, indexed in Pubmed: 28832482.

17. Adzick NS, Thom EA, Spong CY, et al. MOMS Investigators. A randomized trial of prenatal versus postnatal repair of myelomeningocele. $\mathrm{N}$ Engl J Med. 2011;364(11): 993-1004, doi: 10.1056/NEJMoa1014379, indexed in Pubmed: 21306277.

18. Blumenfeld $\mathrm{YJ}$, Belfort MA. Updates in fetal spina bifida repair. Curr Opin Obstet Gynecol. 2018; 30(2): 123-129, doi: 10.1097/GCO.0000000000000443, indexed in Pubmed: 29489502.

19. Wilson RD, Lemerand K, Johnson MP, et al. Reproductive outcomes after pregnancy complicated by maternal-fetal surgery. Am J Obstet Gynecol. 2004; 191(4): 1430-1436, doi: 10.1016/j.ajog.2004.05.054, indexed in Pubmed: 15507978 .

20. Bruner JP, Tulipan NE, Richards WO. Endoscopic coverage of fetal open myelomeningocele in utero. Am J Obstet Gynecol. 1997; 176(1 Pt 1): 256-257, indexed in Pubmed: 9024126.

21. Kohl T, Hering R, Heep A, et al. Percutaneous fetoscopic patch coverage of spina bifida aperta in the human--early clinical experience and potential. Fetal Diagn Ther. 2006; 21(2): 185-193, doi: 10.1159/000089301, indexed in Pubmed: 16491001.

22. Verbeek RJ, Heep A, Maurits NM, et al. Fetal endoscopic myelomeningocele closure preserves segmental neurological function. Dev Med Child Neurol. 2012; 54(1): 15-22, doi: 10.1111/j.1469-8749.2011.04148 $x$, indexed in Pubmed: 22126123.

23. Shurtleff $D$. Fetal endoscopic myelomeningocele repair. Dev Med Child Neurol. 2012; 54(1):4-5, doi: 10.1111/j.1469-8749.2011.04141.x, indexed in Pubmed: 22126087.

24. Arens $C$, Koch C, Veit M, et al. Anesthetic Management for Percutaneous Minimally Invasive Fetoscopic Surgery of Spina Bifida Aperta: A Retrospective, Descriptive Report of Clinical Experience. Anesth Analg. 2017; 125(1): 219-222, doi: 10.1213/ANE.0000000000001896, indexed in Pubmed: 28244950.

25. Kohl T. Percutaneous minimally invasive fetoscopic surgery for spina bifida aperta. Part I: surgical technique and perioperative outcome. UItrasound Obstet Gynecol. 2014; 44(5):515-524, doi: 10.1002/uog.13430, indexed in Pubmed: 24891102 
26. Degenhardt J, Schürg R, Winarno A, et al. Percutaneous minimal-access fetoscopic surgery for spina bifida aperta. Part II: maternal management and outcome. Ultrasound Obstet Gynecol. 2014; 44(5): 525-531, doi: 10.1002/uog.13389, indexed in Pubmed: 24753062.

27. Pedreira DAL, Zanon N, Nishikuni K, et al. Endoscopic surgery for the antenatal treatment of myelomeningocele: the CECAM trial. Am J Obstet Gynecol. 2016; 214(1): 111.e1-111.e11, doi: 10.1016/j.ajog.2015.09.065, indexed in Pubmed: 26386383.

28. Belfort MA, Whitehead WE, Bednov A, et al. Fetoscopic Repair of Meningo-myelocele. Obstet Gynecol. 2015; 126(4): 881-884.

29. Belfort MA, Whitehead WE, Shamshirsaz AA, et al. Fetoscopic Open Neural Tube Defect Repair: Development and Refinement of a Two-Port,
Carbon Dioxide Insufflation Technique. Obstet Gynecol. 2017; 129(4): 734-743, doi: 10.1097/AOG.0000000000001941, indexed in Pubmed: 28277363.

30. Johnson MP, Bennett KA, Rand L, et al. The Management of Myelomeningocele Study: obstetrical outcomes and risk factors for obstetrical complications following prenatal surgery. Am J Obstet Gynecol. 2016; 215(6): 778.e1-778.e9, doi: 10.1016/j.ajog.2016.07.052, indexed in Pubmed: 27496687.

31. Herrera SR, Leme RJ, Valente PR, et al. Comparison between two surgical techniques for prenatal correction of meningomyelocele in sheep. Einstein (Sao Paulo). 2012; 10(4): 455-461, indexed in Pubmed: 23386086. 